\title{
A Notation Method for Three Dimensional Hand Gesture
}

\author{
Eunjung Choi, Heejin Kim, Min K. Chung \\ Department of Industrial and Management Engineering, POSTECH, Pohang, 790-784
}

\begin{abstract}
Objective: The aim of this study is to suggest a notation method for three-dimensional hand gesture. Background: To match intuitive gestures with commands of products, various studies have tried to derive gestures from users. In this case, various gestures for a command are derived due to various users' experience. Thus, organizing the gestures systematically and identifying similar pattern of them have become one of important issues. Method: Related studies about gesture taxonomy and notating sign language were investigated. Results: Through the literature review, a total of five elements of static gesture were selected, and a total of three forms of dynamic gesture were identified. Also temporal variability(reputation) was additionally selected. Conclusion: A notation method which follows a combination sequence of the gesture elements was suggested. Application: A notation method for three dimensional hand gestures might be used to describe and organize the user-defined gesture systematically.
\end{abstract}

Keywords: Three-dimensional hand gesture, Hand gesture notation method, Gesture elements, Gesture features

\section{Introduction}

최근 기기와의 자연스러운 상호작용에 대한 사용자의 요 구가 확대됨에 따라 이를 충족시켜 주기 위한 다양한 접근 들이 시도되고 있다. 이러한 시도 중 전통적인 입력 장치의 도움 없이 디지털 시스템이 응답할 수 있는 물리적 움직임을 이용한 제스처 인터페이스는 기존 널리 사용되던 WIMP (Window, Icon, Menu, Pointing device) 방식의 인터페이스 를 대체하는 NUI(Natural user interface)로서 새롭게 주 목 받고 있다(Park, 2012; Saffer, 2008). 특히, 핸드 제스 처는 다양한 표현이 가능하고 기기의 인식률이 높아 다양한 연구에서 활용되고 있다(Bhuiyan and Picking, 2011).

제스처 인터페이스와 관련한 초기 연구는 제스처 인식기 술 향상에만 중점을 두고 이루어졌으나, 최근 Microsoft 사 의 Kinect와 같이 3차원 공간에서 별도의 장비 없이 사용자 의 제스처를 인식하는 기술이 향상되고 보급됨에 따라 기기
에 적용할 자연스러운 제스처를 도출하는 연구로 점차 확대 되고 있다(Henze et al., 2010; Kuhnel et al., 2011; Mauney et al., 2010; Neßelrath et al., 2011; Nielsen et al., 2003; Nielsen et al., 2004; Wobbrock et al., 2009). 이러한 연 구들은 기기를 작동시키기 위한 명령어와 연관된 사용자의 경험을 최대한 활용하기 위하여 제스처 도출 시 사용자를 직접 참여시키고 있으며, 사용자가 가장 많이 도출한 제스처 를 대상으로 사용성 평가를 수행한 후 최종 제스처를 제안하 고 있다.

상기 방법을 사용할 경우, 사용자의 경험에 따라 다양한 동작이 도출됨으로 이를 일관된 형태로 정리하고, 이를 통해 유사한 제스처 패턴을 찾아내는 과정은 매우 중요하다. 그러 나 대부분의 연구들에서 사용자로부터 수집된 동작을 유사 한 제스처로 분류하는 과정은 연구자의 직관에 의하여 매우 주관적으로 이루어지고 있으며, 제스처의 외형적 요소를 체 계적으로 분류하는 기술적 수준(Descriptive label) 과 관련 한 연구의 부족이 그 원인 중 하나로 지적되고 있다(Park,

Corresponding Author: Min K. Chung. Department of Industrial and Management Engineering, POSTECH, Pohang, 790-784.

Phone: +82-54-279-2192, E-mail: mkc@postech.ac.kr

Copyright@2012 by Ergonomics Society of Korea(pISSN:1229-1684 eISSN:2093-8462). All right reserved.

(c) This is an open-access article distributed under the terms of the Creative Commons Attribution Non-Commercial License(http://creativecommons.org/licenses/by-nc/3.0/), which permits unrestricted non-commercial use, distribution, and reproduction in any medium, provided the original work is properly cited. http://www.esk.or.kr 
2012).

핸드 제스처의 외형적인 형태 및 변화를 구분하기 위한 기술적 수준의 몇몇 연구가 있었다(David and Rajasekaran, 2009; Karam and Schraefel, 2005; Lao et al., 2009; Nielsen et al., 2008; Park, 2012; Quek et al., 2002; Wobbrock et al., 2009). 초기 기술적 수준의 연구는 시간 흐름에 따른 손의 움직임의 유무에 따라 제스처를 단순히 Static 제스처와 Dynamic 제스처로만 구분하였으나(David and Rajasekaran, 2009; Karam and Schraefel, 2005; Nielsen et al., 2008; Quek et al., 2002), 최근에는 제스처 의 세부 요소를 정의하고 제스처를 기록하기 위한 방법을 제안하는 연구들이 수행되고 있다(Lao et al., 2009; Park, 2012; Wobbrock et al., 2009). 그러나 상기 연구들은 터 치스크린 상에서 사용되는 2 차원의 핸드 제스처를 대상으로 함으로 보다 다양한 표현이 가능한 3차원 핸드 제스처를 구 분하기 위한 기준으로 그대로 적용시키기에는 한계가 있다.

$\mathrm{HCI}$ (Human Computer Interaction) 분야에서 3차원 핸 드 제스처를 기록하기 위한 방법으로는 $\mathrm{Mo}$ (2007)가 제시 한 GeLex가 있다. GeLex는 핸드 제스처를 묘사하기 위하 여 핸드 제스처의 세부 요소들을 정의하고 세부 요소들의 조합 방법을 정의한 것으로, $\mathrm{Mo}(2007)$ 는 GeLex를 이용하 여 ASL (American Sign Language) 의 41가지 기본 손 형 태가 모두 표기됨을 확인하였다. 그러나 GeLex 역시 손 동 작에만 한정되어 있으므로, 손과 팔의 움직임 및 손의 위치 등의 요소가 포함되는 3 차원 핸드 제스처를 정확하게 기록 하기에는 한계가 있다.

한편, 3 차원 핸드 제스처의 외형적인 형태 및 변화를 기 록하기 위한 연구는 주로 수화를 중심으로 이루어져 왔다 (Lee and Song, 2006; Quek et al., 2002; Stokoe, 1960; Sutton, 1981). 수화에서 의미를 구분하는 가장 작은 단위 인 수화소(Chereme)는 손의 모양인 수형, 수화가 이루어 지는 공간인 수위, 손의 움직임을 의미하는 수동, 손바닥 또는 손가락의 방향을 의미하는 수향으로 구성되어 있으며 (Stokoe, 1960), 상기 연구들은 이들의 조합으로 복잡한 수 화 동작을 기록하는 방법을 제안하고 있다. 이 중 가장 효 과적으로 받아들여지고 있는 방법으로는 Sutton(1981)의 SignWriting이 있지만, 600개가 넘는 심볼로 수화를 표기 하기 때문에 해당 심볼을 모두 암기해야 한다는 어려움이 있다.

본 연구는 사용자들로부터 도출된 핸드 제스처를 효과적 으로 표기할 수 있는 방법을 제안하는 것을 목적으로 한다. 이를 위하여 제스처의 기술적 수준을 다룬 관련 연구들과 수화에 관한 문헌조사를 실시하였으며, 이를 기반으로 핸드 제스처의 구성 요소를 정의하고 각 구성 요소의 조합 순서 에 따른 제스처 표기법을 제안하였다.

\section{Literature Review}

\subsection{Descriptive study for gesture taxonomy}

기술적 수준의 제스처 분류는 제스처의 움직임 $(\mathrm{Move}-$ ment)이나 자세(Posture) 와 같이 시각적으로 관찰되는 제 스처의 외형적인 형태(제스처 요소)에 따라 해당 제스처를 구분하는 방식을 의미한다(Nielsen et al., 2008). 이러한 분류는 제스처 동작을 효과적으로 기록하고, 일관된 형태로 정리하기 위해 필수적이지만 아직 구체적인 연구가 부족한 실정이다(Park, 2012).

초기 기술적 수준의 제스처 분류 연구에서는 시간흐름 에 따른 손의 움직임 유무에 따라 제스처를 크게 Static과 Dynamic 제스처로 구분하였다(David and Rajasekaran, 2009; Karam and Schraefel, 2005; Nielsen et al., 2008; Quek et al., 2002). Static 제스처는 손이나 손가락의 움직 임 없이 특정 형태 또는 위치로 표현하는 제스처를 의미한 다. 예를 들어, 긍정을 표현하기 위하여 손으로 오케이(뽸) 형태를 묘사하는 것이 이에 해당한다. 반면, Dynamic 제스 처는 시간흐름에 따라 손이나 손가락의 형태가 변하거나 손이 일정 경로를 따라 움직이는 것을 의미한다. 즉, Static 제스처가 단일 이미지를 묘사하는 것이라면, Dynamic 제 스처는 이미지들의 연속적인 나열을 의미한다(David and Rajasekaran, 2009).

최근 사용자에게서 도출된 제스처를 보다 효과적으로 표 기하고 정리하기 위하여 터치스크린상에서 사용되는 제스처 요소를 정의하고 해당 제스처를 분류하기 위한 기준을 정의 하는 연구들이 수행되었다(Lao et al., 2009; Park, 2012; Wobbrock et al., 2009). Wobbrock et al. (2009)는 사용자 로부터 도출된 제스처의 형태를 분류하는 6 가지 기준 Static pose, Dynamic pose, Static pose and path, Dynamic pose and path, One-point touch, One-point path을 정의하였 다. 그러나 분류 기준이 너무 포괄적이고 모호하여, 복잡한 제스처를 명확히 묘사하기에는 적합하지 않다.

Lao et al. (2009)는 터치스크린 상에서 나타날 수 있는 제스처 유형을 터치 유형(Touch styles) 과 움직임 유형 (Movement types)으로 나누어 정의하고, 이를 Transition diagram으로 표기하는 방식을 제안하였다. 터치 유형은 사용 자가 터치스크린에 손을 대는 유형에 따라 연속적 접촉과 비 연속적 접촉으로 나누었고, 움직임 유형은 두드림(Tapping), 누름(Pressing), 끎(Dragging)으로 구분하였다. 그러나 해 당 제스처 유형은 너무 단순화되어 있어 다양한 제스처들을 정확히 묘사하기 어려우며, Diagram 표기 방식 역시 매우 복잡하고 비효율적이라는 한계가 있다(Park, 2012).

$\operatorname{Park}$ (2012)은 제스처 요소를 구체적으로 정의하기 위하 
여 총 69건의 터치 제스처와 관련된 기존 문헌을 정리하여 제스처 동작을 요약하였고, 이를 기반으로 실험에서 사용자 들이 실제 도출한 제스처 동작을 관찰하여 Static 제스처와 Dynamic 제스처의 특성을 포함하는 총 6가지 Posture, Location, Touch, Pose, Path, Device 제스처 요소를 정의 하였다. 또한, 상기 6 가지 제스처 요소의 조합을 통하여 제 스처를 표기하는 방식을 제안하였으며, 기술 방식을 단순화 하기 위하여 6 가지 구성 요소의 기준이 되는 동작을 정의하 였다. 그러나 Park의 연구는 터치스크린 상을 탑재한 모바 일 기기의 제스처로 대상을 한정하고 있어 본 연구의 대 상인 3차원 핸드 제스처와 관련이 없는 Touch 요소 또는 Device 요소를 포함하고 있다. 또한 3차원 공간을 활용한 핸드 제스처는 다양한 표현이 가능함으로 2 차원 제스처를 대상으로 한 Park(2012)의 연구를 그대로 적용하기에는 한계가 있다.

한편, 3 차원 핸드 제스처에 대한 기술적 수준에서의 제스 처 표기와 관련한 연구는 $\mathrm{Mo}(2007)$ 의 연구 외에는 찾을 수 없었다. $\mathrm{Mo}(2007)$ 는 핸드 제스처 동작을 효과적으로 기록하기 위하여 손 동작을 기준으로 제스처 요소를 세부적 으로 정의하고 제스처를 묘사하기 위한 방법으로 GeLex 를 제안하였다. GeLex는 핸드 제스처의 기준이 되는 손가 락 자세(Finger Poses), 손가락 간의 관계(Finger InterRelations), 기본적인 손 형태(Base-Pose)를 정의하고 이 들의 조합으로 핸드 제스처를 표기하고 있다. 또한 해당 기 준에 숫자코드를 정의하여 제스처의 형태를 숫자 표기만으 로도 효과적으로 표기할 수 있도록 하였다. GeLex는 손 모 양과 손 모양의 변화를 기록하기에는 효율적이지만, 손 위치, 손 방향, 팔의 움직임 등 핸드 제스처의 다양한 요소들을 포 함하고 있지 않으므로 보다 명확한 제스처 표기를 위하여 이 를 보안할 필요가 있다.

\subsection{Study for notating sign language}

수화는 일상에 다양하고 복잡한 의사를 전달할 수 있는 언어이며, 잘 정의되어 있고 체계화된 제스처로 상징적 의 사소통을 위한 모든 언어적 정보를 전달한다(Qeuk et al., 2002). 수화를 이루는 기본 단위인 수화소를 분류하고 이를 이용하여 수화를 표기하고자 하는 시도는 1960년대 이전부 터 진행되어 왔다.

Stokoe(1960)은 수화의 단어를 만드는 기본 단위인 수 화소에 대하여 처음으로 구조적인 기술을 하였다. Stokoe (1960)은 수화를 이루는 기본 단위로 손 모양(Handshape), 손의 위치(Location), 손 이동(Movement)의 세 가지를 추 출하였으며, 각각 19 개, 12 개, 24 개의 수화소를 설정하고 이 를 조합하여 수화를 표기하였다. Stokoe(1960)는 수화소를
통하여 수화를 구조적으로 표기할 수 있는 방법을 제시하였 다는 의의가 있으나, 표기방법에서는 수화의 순차적인 변화 과정 (sequential processes)을 고려하지 않았기 때문에 한 번의 이동을 포함한 수화와 반복적인 이동이 있는 수화를 구분할 수 없다.

Sutton(1981)는 손(Hand)뿐만 아니라 팔(Arm)과 몸 (Body)의 움직임(Movements)과 위치(Positions), 손바 닥 방향(Palm orientation), 수화사용 공간(Signing space and planes), 얼굴 표정(Facial expressions), 구두점 (Punctuation), 문법(Grammar)을 심볼로 나타내는 수화 표기법을 제시하였다. Sutton(1981)이 제시한 수화표기 방법인 SignWriting은 손(Hand), 이동(Movement), 얼굴 (Face), 머리(Head), 상체(Upper-body), 팔(Limb), 전신 (Full-body), 위치(Location), 역학(Dynamics), 구두점 (Punctuation)의 10 가지 구성 요소의 조합으로 수화를 표 기하기 때문에 수많은 수화를 자유롭게 표현할 수 있다는 장점이 있다. 이는 앞서 제시한 Stokoe(1960)의 표기법이 손 모양, 손의 위치, 손 이동의 3 가지 구성 요소의 조합으로 수화를 표기한 것에 비해 확장된 형태의 제시방법이라고 할 수 있다. 그러나 표기를 위하여 600개가 넘는 심볼을 모두 암기해야 한다는 어려움이 있다.

한편, Lee and Song (2006)은 한글수화에 이용되는 수화 소를 손의 이동 방향, 손가락 모양, 손의 방향, 사용하는 손 의 수 및 손의 현재 위치 등 5 가지로 분류하고 표기하였다. 이를 위하여 상기 5 가지 수화소를 세부적으로 17 개의 손의 이동 방향, 17 개의 손가락 모양, 손바닥과 손등을 포함하는 2 개의 손의 방향, 한 손 또는 양 손을 포함하는 2 개의 손의 수로 구분하였으며, 손의 현재 위치를 머리영역에서 가슴영 역까지 전체 8 개의 영역으로 분류하고 이들의 조합으로 수 화를 표기하였다. 또한 제안된 수화 표기방법을 한글수화의 단어 및 문장에 적용하여 제안된 수화표기방법으로 표현됨 을 보였다. 그러나 상기 표기법의 경우 각 수화소의 형태를 모드 코드화하고 있어 표기를 위해 46 개의 코드를 모두 확 인해야 한다는 어려움이 있다.

\section{Elements of Three Dimensional Hand Gesture and Notation}

핸드 제스처의 구성 요소를 찾기 위하여 터치스크린에서 의 제스처 요소 및 제스처 분류 기준을 정의한 기존 연구 (Lao et al., 2009; Park, 2012; Wobbrock et al., 2009) 와 핸드 제스처를 사용하는 대표적인 분야인 수화를 참고하 였다. 또한 핸드 제스처를 구성하는 세부적인 구성 요소를 
Table 1. Elements of three dimensional hand gesture

\begin{tabular}{|c|c|c|}
\hline Group & Sub-group & Elements of a hand gesture \\
\hline \multirow{5}{*}{ Static } & Hand Location & A physical location where hand gesture takes place \\
\hline & Hand Entities & $\begin{array}{l}\text { Basic entities composing hands } \\
\text { - Hand(One Hand, Two Hands) } \\
\text { - Finger Digits(Thumb, Index Finger, Middle Finger, Ring Finger, Little Finger) }\end{array}$ \\
\hline & Hand Shape & $\begin{array}{l}\text { A hand shape is determined by combination of finger pose and finger inter relations } \\
\text { - Finger Pose(Point, Bendhalf, Bend, Closehalf, Close) } \\
\text { - Finger Inter Relations(Group, Separate, Cross, Touch) }\end{array}$ \\
\hline & Arm Shape & $\begin{array}{l}\text { An arm shape is determined by a location of an elbow from the body } \\
\text { - A Location of an Elbow(Adduction/Abduction, Flexion/Extension) }\end{array}$ \\
\hline & Palm Orientation & $\begin{array}{l}\text { A direction of palm based on a body } \\
\text { - Palm Orientation(Top, Bottom, Right, Left, Near, Far) }\end{array}$ \\
\hline \multirow{4}{*}{ Dynamic } & Hand Shape Transition & $\begin{array}{l}\text { A hand shape at the start point is different from a hand shape at the end point } \\
\text { - Start Hand Shape => End Hand Shape }\end{array}$ \\
\hline & Hand Transition & $\begin{array}{l}\text { Path } \\
\text { - Translation, Circle(Clockwise, Counterclockwise) } \\
\text { - Hand Location } \\
\text { Hand Movement } \\
\text { - Wrist Movement(Flexion/Extension, Clockwise Rotation/Counterclockwise Rotation) } \\
\text { - Elbow Movement(Adduction/Abduction, Flexion/Extension) } \\
\quad \text { - Hand Location }\end{array}$ \\
\hline & & $\begin{array}{l}<\text { Hand Shape Transition> } \\
\text { A hand shape at the start point is different from a hand shape at the end point } \\
\text { - Start Hand Shape => End Hand Shape }\end{array}$ \\
\hline & $\begin{array}{l}\text { Hand Shape Transition \& } \\
\text { Hand Transition }\end{array}$ & $\begin{array}{l}<\text { Hand Transition> } \\
\text { Path } \\
\text { - Translation, Circle(Clockwise, Counterclockwise) } \\
\text { - Hand Location } \\
\text { Hand Movement } \\
\text { - Wrist Movement(Flexion/Extension, Clockwise Rotation/Counterclockwise Rotation) } \\
\text { - Elbow Movement(Adduction/Abduction, Flexion/Extension) } \\
\quad \text { - Hand Location }\end{array}$ \\
\hline \multicolumn{2}{|c|}{ Temporal Variability } & Reputation(Number of reputation) \\
\hline
\end{tabular}

파악하기 위하여 GeLex를 제안한 $\mathrm{Mo}(2007)$ 의 연구를 참 고하였다.

이를 통해 시간흐름에 따른 손의 움직임 유무에 따라 핸 드 제스처의 형태를 크게 Static 제스처와 Dynamic 제스처 로 구분하였으며, Static 제스처를 핸드 제스처의 기본 형태 로 정의하였다. 이는 Dynamic 제스처는 단일 이미지를 묘 사한 Static 제스처의 연속적 나열을 의미한다는 David and Rajasekaran(2009)의 연구에서 착안하였다. 또한, 상기 연 구들을 바탕으로 Static 제스처를 구성하는 5 가지 세부 구성 요소를 추출하였으며, Static 제스처가 Dynamic 제스처로 조합되는 3 가지 형태를 추출하였다. 마지막으로, Static 또는 Dynamic 제스처의 반복되는 횟수를 의미하는 시간적 변화 요소를 추가하였다(Table 1).

한편, 핸드 제스처를 표기하는 방식은 GeLex (Mo, 2007)
의 표기 방식을 채택하여 이를 본 연구에 확장 및 적용시켰 다. GeLex는 ASL (America Sign Language)의 41개 기본 수화 형태를 간단한 숫자 조합만으로 모두 표기할 수 있다는 점에서 손의 형태를 묘사하는 표기법으로 활용가치가 높다 고 판단된다. 본 연구에서 선정한 핸드 제스처 구성 요소 및 각 요소의 표기법은 다음과 같다.

\subsection{Elements of static gesture and notation}

Static 제스처 특성을 갖는 요소로는 총 5 개 요소 핸드 제스처 위치(Hand Location), 손 세부 구성 요소(Hand Entities), 손 형태(Hand Shape), 팔 형태(Arm Shape), 손바닥 방향(Palm Orientation)이 있다. 


\subsubsection{Hand location}

핸드 제스처 위치는 사용자가 제스처를 취하는 동안 손이 놓인 위치를 의미하며, 허리에서 머리 위, 어깨에서 양 옆으 로 떨어진 공간 등 팔이 뻗을 수 있는 범위 내 공간을 의미 하는 수화의 조음 공간을 차용하였다. 제스처가 이루어지는 공간 내에서 손의 위치를 표기하기 위하여 McNeill(1992) 의 Gesture Space를 수정하여 Figure 1과 같이 앉은 자세 를 중심으로 어깨, 몸통, 배를 기준으로 공간을 9 등분으로 나누어 각 공간에 번호를 부여하였다.

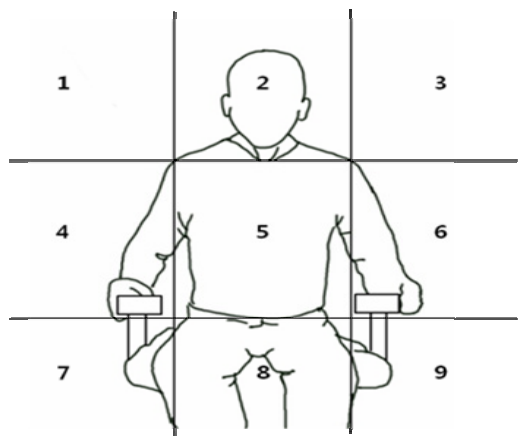

Figure 1. Hand location

\subsubsection{Hand entities}

손 구성 요소는 크게 손의 개수와 손가락의 종류를 의미 한다. 손 구성 요소의 표기 방식은 GeLex $(\mathrm{Mo}, 2007)$ 표기 법을 차용하여 정의하였다. 한 손을 사용한 제스처의 경우 주 사용 손이 오른손일 경우 1 로 왼손일 경우 2 로 표기한다. 손가락의 종류는 $\mathrm{Fi}$ 를 사용하며, 엄지를 기준으로 $\mathrm{F} 1$ (엄지), $\mathrm{F} 2$ (검지), F3(중지), F4(약지), F5(새끼 손가락)로 표기 한다.

\subsubsection{Hand shape}

손 형태는 기본적인 손가락 자세와 손가락 간의 관계의 조 합으로 이루어지는 핸드 제스처의 기본적인 형태를 의미한 다. 손 형태는 손바닥 방향이 몸 바깥쪽을 향하는 상태를 기 본 형태로 시작하여 조합한다. 손 형태 표기 방식은 GeLex (Mo, 2007) 표기법을 그대로 차용하였다. 우선 기본적인 손 가락 자세는 Figure 2와 같이 Point(UP), Point(Forward), Point(Side), Bendhalf, Bend, Closehalf, Close가 있으며, 해당 자세의 표기를 위하여 1 7의 숫자를 부여하였다. 손가 락 간의 관계는 Figure 3과 같이 Separate, Group, Cross (Fi in front of $\mathrm{Fj}$ ), Cross ( $\mathrm{Fj}$ in front of $\mathrm{Fi}$ ), Touch, Loop 가 있으며, 해당 관계의 표기를 위하여 1 6의 숫자를 부여
하였다. 따라서 손 형태는 각 해당 손가락의 자세를 앞에 표 기하고(F1, F2, F3, F4, F5), 손가락 간의 관계를 뒤에 표기 하여 (F12, F13, F14, F15, F23, F34, F45) 기록할 수 있 다. $\mathrm{Fij}$ 는 $\mathrm{Fi}$ 손가락과 $\mathrm{Fj}$ 손가락 간의 관계를 의미한다. 예 를 들어, 주먹을 쥔 형태(의)는 $(17777 ; 2111222)$ 로 표기 할 수 있다.

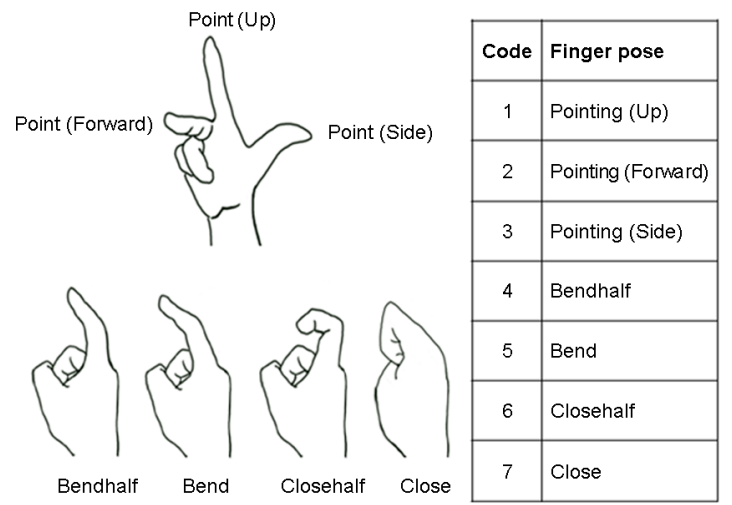

Figure 2. Hand pose

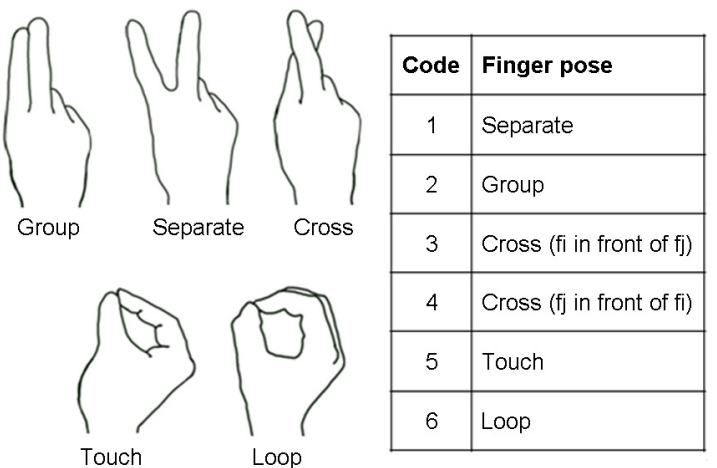

Figure 3. Hand inter relations

\subsubsection{Arm shape}

팔 형태는 전체적인 팔의 형태를 의미하며 팔꿈치가 위치 한 정도 또는 팔꿈치 굴절 유무에 따라 표현한다. 팔꿈치와 몸통 간의 거리에 따라 팔꿈치가 몸통과 가까운 곳에 위치한 형태를 내전(Adduction)으로 팔꿈치가 몸통과 먼 곳에 위 치한 것을 외전(Abduction)으로 표현한다. 또한 팔꿈치의 굴절 유무에 따라 팔꿈치가 굽혀진 상태를 굴곡(Flexion)으 로 팔꿈치가 펴진 상태를 신장(Extension)으로 표현한다 (Figure 4). 이때, 팔꿈치 위치 정도를 앞에 팔꿈치 굴절 유 무는 뒤에 ','를 이용하여 표기하며, 내전은 1-1로 외전은 1-2로 표기하며, 굴곡은 2-1로 신장은 2-2로 표기한다. 


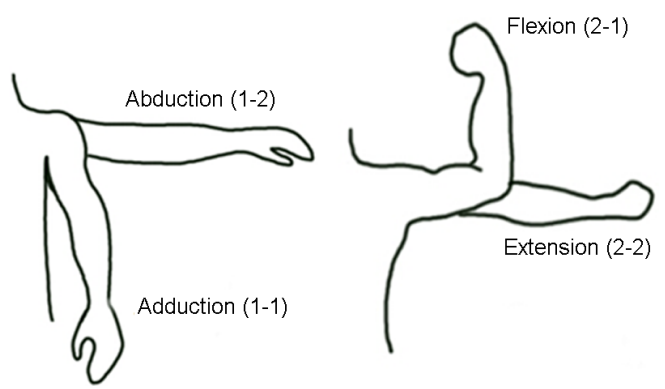

Figure 4. Arm shape

\subsubsection{Palm orientation}

손바닥 방향은 몸통을 중심으로 손바닥이 가리키는 방향 을 의미하며, 상(Top), 하(Bottom), 우(Right), 좌(Left), 몸 쪽(Near), 몸 바깥쪽 (Far)을 포함한다. 각 방향은 1 6 의 숫자로 표기한다.

\subsection{Elements of dynamic gesture and notation}

Static 제스처가 Dynamic 제스처로 조합되는 3가지 형태 는 손 형태 변화(Hand Shape Transition), 손 이동(Hand Transition), 손 형태 변화와 손 이동 동시 발생 (Hand Shape Transition and Hand Transition)이 있다. Dynamic 제스처 요소에서 변화량에 대하여는 '=>' 기호를 사용하여 제스처의 시작과 끝 자세의 변화량을 표기한다. Dynamic 제 스처는 여러 단계의 Static 제스처의 조합으로 이루어지지만, 처음과 끝 자세 사이의 변화에 일반적인 경로가 있으므로 처음 자세와 끝 자세만을 표기하는 것만으로도 Dynamic 제스처를 묘사하기 충분하다(Lin et al., 2004, Mo, 2007; Witkin and Kass, 1988; Wu et al., 2001). 한편, Static 또 는 Dynamic 제스처의 반복되는 횟수를 의미하는 시간적 변 화 요소에 대하여는 'X 배수(숫자)'로 표기한다.

\subsubsection{Gesture that accompanies hand shape transition}

손 형태 변화는 다른 Static 제스처의 세부 요소의 변화 없이 손의 전반적인 형태만이 변화는 것을 의미한다. 예를 들어, 주먹을 쥐었다 손을 활짝 펴는 제스처가 이에 해당한 다. 이 경우 처음과 끝 자세의 손 형태(Hand Shape)를 표 기한다.

\subsubsection{Gesture that accompanies hand transition}

손 이동은 손 형태(Hand Shape) 이외의 다른 Static 제 스처의 세부 요소들이 변하는 것으로, 크게 경로 운동, 손 운동, 장향(손바닥 방향) 운동이 있으며, 운동의 크기에 따 라 핸드 제스처 위치(Hand Location)가 변할 수 있다.
경로 운동(Path)은 Static 제스처가 이동한 경로를 나타 내는 것으로 궤적 운동(Transition Movement) 과 원 운동 (Circle Movement)이 이에 속한다. 궤적 운동의 경우 1 로 표기하며, 현재 손의 위치를 원점 $(0,0,0)$ 으로 하고 Static 제스처가 이동한 궤적을 Figure 5 와 같이 X, Y, Z 축을 이 용하여 표기한다. 이때, 이동 방향에 따라 앞, 오른쪽, 위 방 향을 1 로 뒤, 왼쪽, 아래 방향을 -1 로 움직임이 없을 경우 를 0 값을 이용하여 표기한다. 원 운동은 시계 방향을 2-1 로 반시계 방향을 2-2로 표기하며, Figure 5 와 같이 X, Y, $Z$ 축을 이용하여 이동 방향을 함께 표현해 준다. 이를 통해 회전 정도(원, 반원 등)를 함께 표기할 수 있다. 경로 운동의 경우 핸드 제스처 공간과 함께 표기해 주며, 핸드 제스처 공 간을 앞에 경로운동 종류와 $\mathrm{X}, \mathrm{Y}, \mathrm{Z}$ 값을 '()' 안에 표기하 며, 이때 ';'를 이용한다. 단, $\mathrm{S}$ 를 묘사하는 경우와 같이 연속 하여 하나의 형태를 이루는 제스처 형태에 대하여는 ' $\&$ '를 사용하여 형태가 하나로 이어져 있음을 표기한다. 단 \& 뒤 에 표기된 경로의 시작점을 원점 $(0,0,0)$ 으로 보고 이동 방 향에 따라 표기한다. 예를 들어, 사용자가 $\mathrm{S}$ 를 그렸을 경우 경로는 $2(0,0,0)=>5(2-2 ; 0,0,-1) \& 5(2-1 ; 0,0,-1)$ 로 표기할 수 있다.

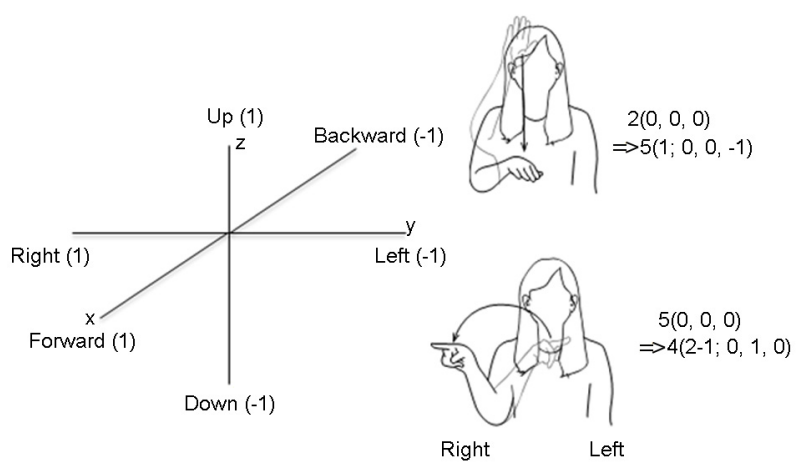

Figure 5. Path movement(a user view point): Transition movement(top), and circle movement(bottom)

손 운동은 Static 제스처가 손목 또는 팔꿈치 관절 움직 임으로 변하는 것을 의미한다. 손목 관절의 움직임의 경우 움직임의 특성에 따라 Figure 6과 같이 관절의 굴절 모양 에 따라 관절을 아래로 구부리는 동작인 굴절(Flexion)과 위쪽으로 뻗는 동작인 신장(Extension)으로 나누며, 관절 을 둥글게 돌리는 동작에 따라 시계방향 회전(Clockwise Rotation) 과 반시계방향 회전(Counterclockwise Rotation) 으로 나눈다. 또한 각각 동작을 $1-1,1-2,2-1,2-2$ 로 표기한다. 팔꿈치 관절의 움직임의 경우 Static 동작에서 팔 형태의 처음과 끝 자세를 각각 기입하여 움직임을 표현 한다. 따라서 상기 Static 구성 요소로서의 팔 형태 표기법 


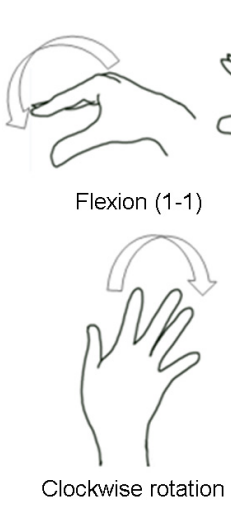

$(2-1)$

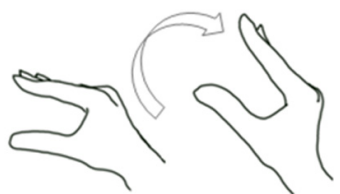

Extension (1-2)

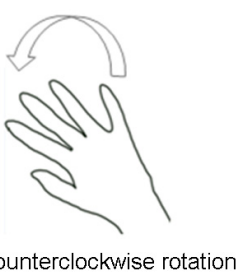

$(2-2)$
Figure 6. Wrist movement

을 그대로 사용한다.

장향 운동은 손바닥 방향이 변하는 것을 의미하며, 처음과 끝 자세를 각각 기입하여 움직임을 표기한다. 장향 역시 상기 Static 구성 요소로서의 장향 기입방법을 그대로 사용한다.

\subsubsection{Gesture that accompanies hand shape transition and hand transition}

손 형태 변화와 손 이동 동시 발생 형태는 하나의 제스처
에서 상기 두 가지 형태 변화가 동시에 발생하는 것을 의미 한다. 예를 들어, 손이 펴진 기본형 Static 제스처가 아래쪽 사선 방향으로 이동하면서 주먹이 쥐어지는 형태가 이에 해당한다. 이 경우 변화된 요소인 핸드 제스처 위치(Hand Location), 손 형태(Hand Shape), 경로 운동(Transition), 장향(Palm Orientation)에 대하여 앞서 언급한 표기 방식을 이용하여 모두 표기해 준다.

\section{Gesture Notation Method}

Figure 7은 제스처의 4가지 형태, Static 제스처, 손 형 태 변화(Hand Shape Transition) 제스처, 손 이동(Hand Transition) 제스처, 손 형태 변화와 손 이동 동시 발생 (Hand Shape Transition and Hand Transition) 제스처에 따라 Table 1에 정리한 제스처 세부 구성 요소들의 표기 순 서를 보여준다. 한 손 제스처의 경우 주 사용 손을 표기하며, 양 손 제스처인 경우 오른손을 위쪽 행에 왼손을 아래쪽 행 에 각각 표기한 후 + 로 연결한다. 이때 오른손을 숫자 1 로 왼손을 숫자 2로 표기한다. Figure 8은 제스처의 세부 구성 요소들을 표기하기 위한 기본 순서이다.

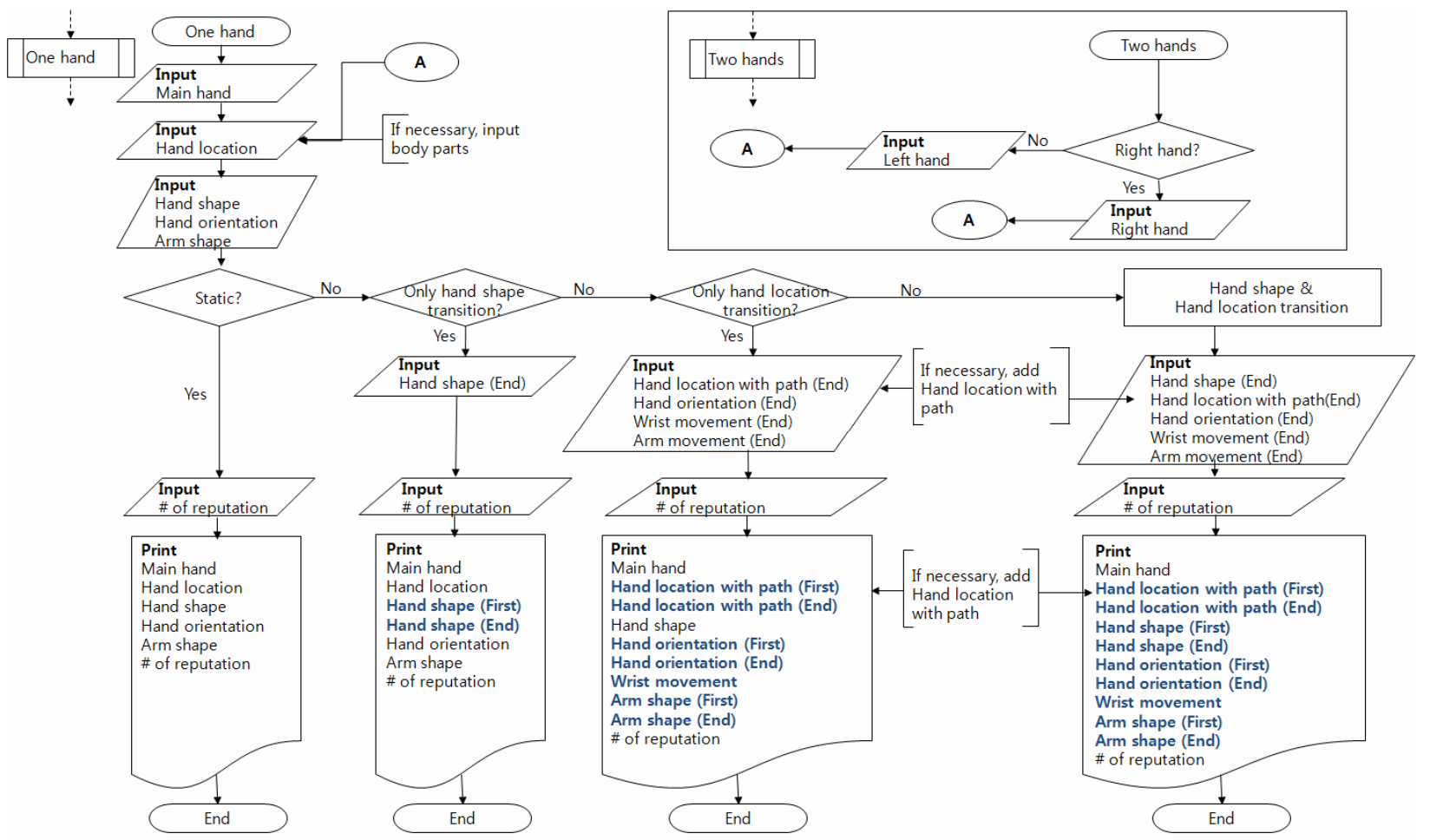

Figure 7. Flow chart of notation 


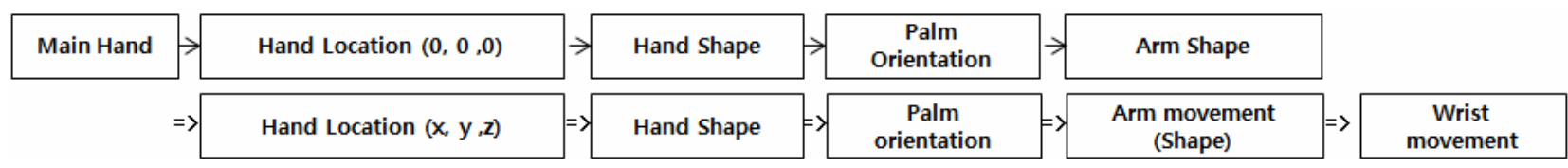

Figure 8. Basic form of notation

핸드 제스처의 기본 형태인 Static 제스처를 기입하는 순 서는 다음과 같다. 우선 손의 종류(오른손, 또는 왼손)을 기 입한 후, 핸드 제스처 위치(Hand Location)를 기입한다. 이 후 손 형태(Hand Shape), 손바닥 방향(Palm Orientation), 팔 형태(Arm Shape)의 조합에 의한 Static 제스처의 전반 적인 모양을 기입한다. 순서도에 따른 Static 제스처의 표기 예시는 Figure 9 와 같다.

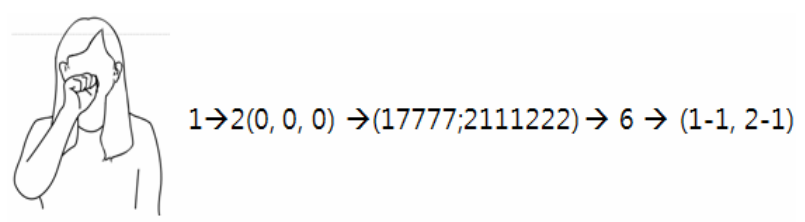

Figure 9. Example of static gesture

손 형태 변화(Hand Shape Transition) 제스처는 제스처 기본 요소 중 손 형태(Hand Shape) 만이 변하는 것으로 핸 드 제스처의 기본 형태를 기입한 후 Figure 10 과 같이 마지 막 손 형태를 추가로 기입한다.

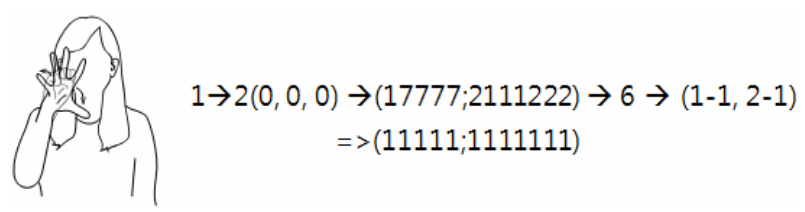

Figure 10. Example of hand shape transition

손 이동(Hand Transition) 제스처는 손 형태(Hand Shape) 이외에 다른 세부 구성 요소들이 변하는 것으로 크 게 네 가지 유형인 경로 운동, 장향(손바닥 방향) 운동, 손목 관절 운동, 팔꿈치 관절 운동을 포함한다. 핸드 제스처의 기 본 형태에서 궤적 운동과 원 운동이 발생한 경로 운동의 경 우 Figure 11 (1st and 2nd line) 과 같이 마지막 핸드 제스 처 위치와 함께 기본 핸드 제스처가 이동한 경로를 추가로 기입하며, 손바닥 방향이 변하는 장향 운동의 경우 Figure 11 (3rd line) 과 같이 마지막 장향을 추가로 기입한다. 또한, 팔꿈치 관절 운동의 경우 Figure 11 (4th line) 과 같이 마지
막 팔 형태를 추가로 기입하며, 손목 관절 운동의 경우 운동 형태를 Figure 11 (5th line) 와 같이 기입한다.
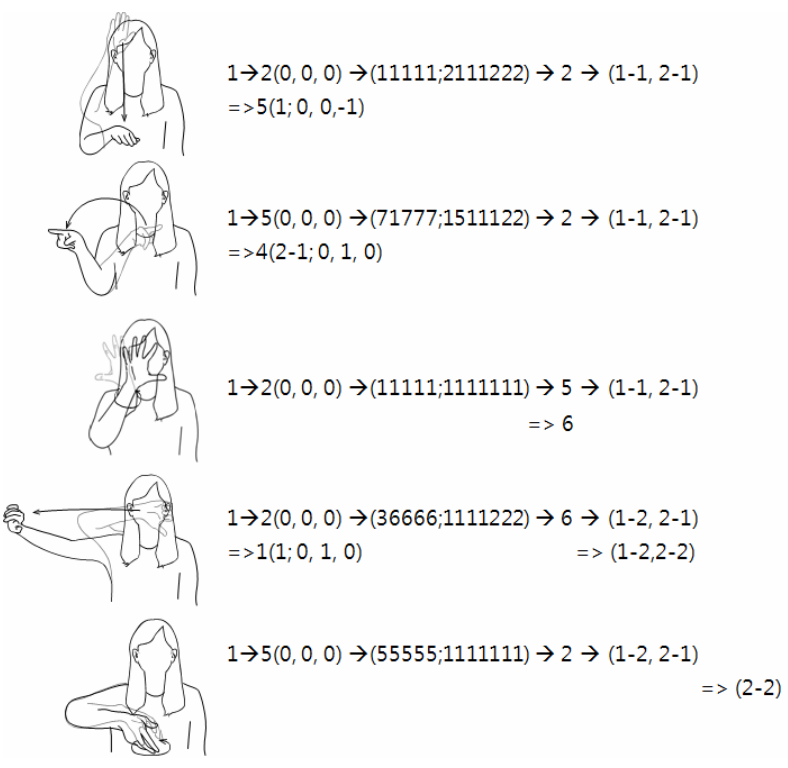

Figure 11. Example of hand transition: Path-transition $\left(1^{\text {st }}\right.$ line $)$, Path-Circle $\left(2^{\text {nd }} l i n e\right)$, hand orientation transition $\left(3^{\text {rd }}\right.$ line $)$, arm movement $\left(4^{\text {th }}\right.$ line $)$, and wrist movement $\left(5^{\text {th }}\right.$ line $)$

손 형태 변화와 손 이동 동시 발생 (Hand Shape Transition and Hand Transition) 제스처의 경우는 기본 형태를 기입한 후 Figure 12와 같이 변화된 요소들을 모두 기입한다. 모든 제스처 형태를 기입한 후 제스처의 반복이 있을 경우 제스처 의 반복 횟수를 ' X 배수'로 기입한다.

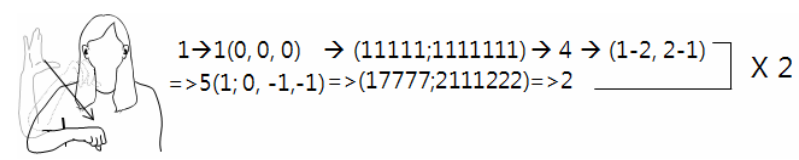

Figure 12. Example of gesture that accompanies hand shape transition and hand transition 


\section{Conclusion}

본 연구는 핸드 제스처 동작을 효과적으로 기록할 수 있 는 표기법을 제안하기 위하여 제스처의 기술적 수준을 다 룬 관련 연구들과, 수화에 관한 문헌조사를 실시하였다. 이 를 통해 총 5 개의 Static 제스처 세부 요소들과 총 3 개의 Dynamic 제스처 형태를 도출하였으며, 제스처의 전반적인 반복 횟수에 해당하는 시간적 요인(Temporal Variability) 을 추가적으로 도출하였다. 또한 상기 제스처 요소들의 조합 순서를 정의하고 이에 따라 제스처를 효과적으로 기록할 수 있는 핸드 제스처 표기법을 제안하였다. 본 연구는 사용자들 로부터 도출된 제스처를 동영상 또는 이미지 이외의 방식을 사용하여 정량적으로 표기할 수 있는 방법을 제안하였다는 점에서 가장 큰 의의가 있으며, 핸드 제스처를 구성하는 제 스처 요인들을 정리하였다는 점에서 의의가 있다.

본 연구에서 제안한 핸드 제스처 표기법은 사용자가 도출 한 제스처를 정리하는데 활용될 수 있으며, 추후 사용자들로 부터 도출된 다양한 제스처들의 유사한 패턴을 찾는데 활용 될 수 있을 것이다. 그러나 본 연구에서는 실제로 사용자를 대상으로 제스처를 도출하고 해당 제스처를 본 연구에서 제 안한 제스처 표기법을 적용하지 않았으므로 이에 대한 추가 적인 연구가 필요하다.

\section{Acknowledgements}

This work was supported by the National Research Foundation of Korea(NRF) grant funded by the Korea government(MEST) (No. 2012-0005482).

This treatise was supported by the project of Global Ph.D. Fellowship which National Research Foundation of Korea conducts from 2011(No. 2011-0007550).

\section{References}

Bhuiyan, M. and Picking, R., A., Gesture controlled user interface for inclusive design and evaluative study of its usability, Journal of software engineering and applications, 4, 513-521, 2011.

David, V. K. and Rajasekaran, S., Retracted chapter: gesture and signature recognition using MicroARTMAP, Studies in Computational Intelligence, 160, 93-113, 2009.

Henze, N., Locken, A., Boll, S., Hesselmann, T. and Pielot, M., "Free-hand gestures for music playback: deriving gestures with a user-centered process", Proceedings of the 9th international conference on Mobile and Ubiquitous Multimedia, 16, 2010.

Karam, M. and Schraefel, M. C., "A taxonomy of gesture in human computer interactions", Technical report, Technical Report ECSTRIAM05-009, Electronics and Computer Science, University of Southampton, 2005.

Kuhnel, C., Westermann, T., Hemmert, F., Kratz, S., Muller, A. and Moller, S., I'm home: Defining and evaluating a gesture set for smart-home control, International Journal of Human-Computer Studies, 693-704, 2011.

Lao, S., Heng, X., Zhang, G., Ling, Y. and Wang, P. A., "Gestural interaction design model for multi-touch displays". Proceedings of the 2009 British Computer Society Conference on Human-Computer interaction, Swinton, UK, (pp. 440-446), 2009.

Lee, B. and Song, P., Advanced representation method of hand motion by cheremes analysis in KSL, Journal of Korea Multimedia Society, 9(8), 1067-1075, 2006.

Lin, J. Y., Wu, Y. and Huang, T. S., "3D model-based hand tracking using stochastic direct search method", Sixth IEEE International Conference on Automatic Face and Gesture Recognition, Seoul, Korea, (pp. 693-698), 2004.

Mauney, D., Howarth, J., Wirtanen, A. and Capra, M., "Cultural similarities and differences in user-defined gestures for touchscreen user Interfaces", Proceedings of the CHI'10, Atlanta, Georgia, USA., 2010.

McNeill, D., Hand and mind: What gestures reveal about thought, University of Chicago Press, 1992.

Mo, Z., Gesture interface engine, Ph.D. thesis; University of Southern California, 2007

Neßelrath, R., Lu, C., Schulz, C. H., Frey, J. and Alexandersson, J., "A gesture based system for context-sensitive interaction with smart homes", DeutscherAAL-Kongress, 2011.

Nielsen, M., Moeslund, T., Storring, T. and Granum, E., "A procedure for developing intuitive and ergonomic gesture interfaces for manmachine interaction", Proceedings of the 5th Interaction Gesture Workshop, Genova, Italy, 2003.

Nielsen, M., Storring, T., Moeslund, T. and Granum, E., A procedure for developing intuitive and ergonomic gesture interfaces for $\mathrm{HCI}$ Gesture-Based Communication in Human-Computer Interaction, 105-106, 2004.

Nielsen, M., Moeslund, T. B. and Granum, S., E., Gesture interfaces, In P. Kortum(Ed.): HCI Beyond the GUI: Design for Haptic, Speech, Olfactory, and Other Nontraditional Interfaces, Elsevier, 2008.

Park, W., A multi-touch gesture vocabulary design methodolgy for mobile devices, Ph.D. thesis; Division of Mechanical and Industrial Engineering POSTECH, Pohang, Korea, 2012.

Quek, F., McNeill, D., Bryll, R., Duncan, S., Ma, X. F. and Kirbas, C. Multimodal human discourse: Gesture and speech, ACM Transactions on Computer-Human Interaction, 9, 171-193, 2002.

Saffer, D., Designing Gestural Interfaces: touchscreens and interactive devices, 1 st ed., O'Reilly Media, 2008.

Stokoe, W. C., Sign language structure: An outline of the visua 
communication system of the American deaf, Studies in Linguistics: Occasional Papers 8, 1960.

Sutton, V., Signwriting for everyday use, Newport Beach: Sutton Movement Writing Press, 1981.

Witkin, A. and Kass, M., "Spacetime constraints", Proceedings of Siggraph, NewYork, USA, (pp. 159-168), 1988.

Wu, Y., Lin, J. Y., and Huang, T. S., "Capturing natural hand articulation", Proceedings of 8th International Conference on Computer Vision, 2, (pp. 426-432), 2001

Wobbrock, J. O., Morris, M. R. and Wilson, A. D., "User-defined gestures for surface computing", Proceedings of the 27th International Conference on Human Factors in Computing Systems, (pp. 1083 -1092), 2009.
Heejin Kim: gimigimi@postech.ac.kr

Highest degree: BS. Department of Industrial \& Management Engineering, POSTECH

Position title: Ph.D. candidate, Department of Industrial \& Management Engineering, POSTECH

Areas of interest: Gesture Interface, User Experiment, Universal Design

Min K. Chung: mkc@postech.ac.kr

Highest degree: $\mathrm{PhD}$, Industrial and Operations Engineering, University of Michigan

Position title: Professor, Department of Industrial \& Management Engineering, POSTECH

Areas of interest: Universal Design, Biomechanics, Applied Statistics, Design of Experiments

Date Received : 2012-07-15

Date Revised :2012-07-29

Date Accepted : 2012-07-30

\section{Author listings}

Eunjung Choi: lovecej@postech.ac.kr

Highest degree: MS, Department of Industrial \& Management Engineering, POSTECH

Position title: Ph.D. candidate, Department of Industrial \& Management Engineering, POSTECH

Areas of interest: Gesture Interface, User Interface, User Experiment 